\author{
Anna Babicka-Wirkus \\ Akademia Pomorska w Słupsku \\ E-MAIL: anna.babicka-wirkus.apsl.edu.pl
}

\title{
Profesjonalizm nauczyciela a kultura praw dziecka w szkole
}

\begin{abstract}
STRESZCZENIE
Artykuł porusza problematykę urzeczywistniania kultury praw dziecka w szkole i roli, jaką w tym procesie odgrywa nauczyciel profesjonalista. Praktykowanie tej kultury w codzienności szkoły jest zadaniem wymagającym posiadania przez nauczyciela nie tylko gruntownej wiedzy na temat praw dziecka i praw człowieka, ale także akceptacji tych idei oraz stworzenia możliwości doświadczania i upominania się o nie w szkole. Akademicki i potoczny dyskurs na temat profesjonalizmu nauczyciela pomija lub marginalnie traktuje ten wymiar, co skutkuje niskim poziomem praktykowania kultury praw dziecka w szkołach. Stan ten ma znaczenie również dla jakości przygotowania obywateli do życia w demokratycznym społeczeństwie obywatelskim, dla którego podstawą są prawa człowieka i prawa dziecka.
\end{abstract}

SŁOWA KLUCZOWE: kultura praw dziecka, profesjonalizm nauczyciela, szkoła

\section{Wprowadzenie}

Problematyka profesjonalizmu nauczycieli jest kwestią szeroko dyskutowaną zarówno na poziomie dyskursu akademickiego (Lawn, 1996; Nowak-Dziemianowicz, 2008; Demirkasīmoğlu, 2010; Madalińska-Michalak, 2014; Gołębniak i Zamorska, 2014), jak i potocznego. Madalińska-Michalak (2014) wskazuje, że profesjonalizm dotyczy kwestii jakości praktyki stosowanej przez osobę wykonującą dany zawód. Profesjonalizm, ogólnie rzecz ujmując, dotyczy kwestii kwalifikacji, nabytych umiejętności oraz kompetencji, jakie są wymagane do skutecznego wykonywania zawodu (Englung, 1996; Demirkasīmoğlu, 2010). Istnieje wiele koncepcji profesjonalizmu, które można podzielić za Snoek (2009) na podejścia: klasyczne, menedżerskie (nowy profesjonalizm), podejście kolektywne, organizacyjne oraz etyczno-altruistyczne. Omawianie ich nie jest jednak celem tego artykułu. Wskazanie tych podejść miało na celu jedynie ukazanie złożoności problematyki profesjonalizmu nauczycieli, który wiąże się z odpowiedziami na wiele kwestii związanych między innymi z zasobem wiedzy, przekonaniami, postawami, jakością wykształcenia, doświadczeniem zawodowym, kompetencjami osób nauczających młode pokolenia. 
$\mathrm{Na}$ potrzeby prowadzonych $\mathrm{w}$ artykule analiz przyjmuję za Kwiatkowską (2008, s. 167-169), że profesjonalizm nauczycielski jest misją, uwidaczniającą się w związku dwóch niepowtarzalnych osób, z których każda obdarzona jest podmiotowością. Jest to relacja między uczniem i nauczycielem, która ugruntowana jest na wysokich standardach poznawczych, etycznych i działaniowych prezentowanych przez nauczyciela. Podkreślenie przez Kwiatkowską umiejętności tworzenia relacji o charakterze podmiotowymi, między osobami, które, jak wynika z codzienności życia szkoły, znajdują się często w relacji hierarchicznej (uprzywilejowany nauczyciel i podporządkowany uczeń) (por. Dudzikowa i Knasiecka-Falbierska (red.), 2013; Dudzikowa i Jaskulska (red.), 2016) stanowi istotę profesjonalizmu nauczycieli. Nabiera ona szczególnego znaczenia w kontekście poruszanej w artykule problematyki.

Celem artykułu jest wzbudzenie refleksji nauczycieli nauczycieli nad potrzebą gruntownego przygotowania przyszłych nauczycieli do implementacji kultury praw dziecka w instytucjach edukacyjnych. Kultura ta ma istotne znaczenie dla rozwoju osobistego i społecznego uczniów. Problem krzewienia kultury praw dziecka w szkole wykracza znacznie poza aspekt teoretycznej wiedzy nauczycieli o prawach dziecka, która, jak wynika z badań, jest niewielka (Kozak, 2014; Babicka-Wirkus, 2015; Jeromie i in., 2015, Babicka-Wirkus i Groenwald, 2018). Niski poziom wiedzy nauczycieli o prawach dziecka uniemożliwia im tworzenie warunków do praktykowania kultury praw dziecka w szkole, ponieważ rzetelna wiedza w tym zakresie jest warunkiem bazowym implementacji wartości, na których opierają się prawa dziecka (Czerepaniak-Walczak, 1997). Sprawa dotyczy rozumienia tych praw przez nauczycieli, ich akceptacji oraz urzeczywistniania w praktyce szkolnej niezależnie od nauczanego przedmiotu. Prawa dziecka nie mogą mieścić się w ramach pojedynczego przedmiotu, lecz muszą wykraczać poza te ramy i stać się kontekstem (przestrzenią) do realizacji treści przedmiotów szkolnych. Wymóg ten jest usankcjonowany prawnie i wynika z ratyfikacji przez Polskę w 1991 roku Konwencji o prawach dziecka (KPD) i w konsekwencji realizacji jej zapisów, o czym mówi artykuł 42. KPD. Aby te zapisy były realizowane, reprezentanci dominujących struktur (w tym wypadku nauczyciele) powinni stworzyć odpowiednie warunki dla doświadczania tych praw w przestrzeni życia szkoły.

Propozycja nowego obszaru dyskusji o profesjonalizmie mieści się w podejściu trialogicznym. Bazuje ono na triadzie: kultura-dialog-działalność. Zakłada się tu, że nauczanie jest działalnością kulturową, która opiera się na zróżnicowaniu, progresywnym dyskursie oraz na wspólnej aktywności. Gołębniak oraz Zamorska (2014, s. 45), charakteryzując to podejście, podają, że „[s]tawanie się nauczycielem to nieustanne re/de/konstruowanie mikro- 
procesów kultury, w których każdy człowiek, a więc także uczeń i nauczyciel, definiuje siebie". Przyjmując, że społeczeństwa demokratyczne wyrastają z idei zakorzenionych w prawach człowieka (Osiatyński, 2011), szczególnego znaczenia nabiera edukacja odbywająca się w przestrzeni szacunku dla tych praw, w przestrzeni realizacji wartości, takich jak godność, wolność, równość i sprawiedliwość (Jabłoński i Jarosz-Żukowska, 2004). Implementacja tych wartości w codzienne życie szkoły możliwa jest jedynie poprzez dialog między równymi podmiotami (uczniem i nauczycielem), których opinie i poglądy są brane pod uwagę i respektowane przez każdą ze stron. W dialogu tym nie ma głosów bardziej lub mniej znaczących, uprzywilejowanych. Jest to przestrzeń dyskusji, niezgody, dyssensu (Rancière, 1999), w której każdy może się wypowiedzieć, a jego/jej pogląd zostanie przyjęty z należytą uwagą. W tym kontekście dialog wymaga zapewnienia uczniom warunków do partycypacji w życiu szkoły i do uczestniczenia w procesie podejmowania decyzji dotyczących istotnych spraw dla uczniów.

\section{Kultura praw dziecka - próba definicji}

Każda szkoła posiada swoją unikalną kulturę, która jest pokłosiem uczestniczących w niej podmiotów, wyznawanych przez nie wartości, kontekstu geograficzno-społeczno-politycznego, w którym jest ulokowana, oraz jej przestrzeni. Kultura szkoły zawsze determinowana jest przez czasowo-przestrzenne warunki historyczne (Klus-Stańska, 2010, s. 307). Czerepaniak-Walczak definiuje kulturę szkoły jako

zwyczaje, mądrości, używanie przedmiotów materialnych, rozumienie i wartościowanie symboli oraz wzory zachowań, przekazywane z pokolenia na pokolenie nauczycieli, uczniów, rodziców i innych osób związanych ze szkołą. Mogą być one powtarzalne, ale mogą być również nowe, nieznane dotychczas (2018, s. 12).

Autorka wskazuje, że kultura szkoły posiada wiele krajobrazów (2015). Składa się ona z dwóch kluczowych elementów, jakimi są: kultura dominująca oraz kultura oporu szkoły (Babicka-Wirkus, 2019). Pierwsza bazuje na hierarchicznej strukturze, w której głos nauczyciela jest ważniejszy niż głos ucznia. Występujący między nimi dialog jest określony przez wpisaną w niego nierówność inteligencji dyskutantów, na którą wskazuje Rancière (1991). Autor przyrównuje tę sytuację do relacji jaka wynika z założenia nierówności inteligencji występującej w relacji, ogłupiający mistrz i jego uczniowie. W tej relacji nauczyciel traktowany jest jako jednokierunkowy transmiter wiedzy, a uczniowie zaś jako jednostki zdolne jedynie do odtworzenia dostarczonej im wiedzy. Kultura oporu zaś jest 
strukturą działań wynikających z poglądów, postaw i relacji bazujących na niezgodzie wobec dominującego porządku. Jest antystrukturą wyłaniającą się z opozycji do dominującej struktury szkoły, czyli obowiązującego porządku aksjonormatywnego, wyznaczającego specyficzny układ relacji między poszczególnymi jej elementami (Babicka-Wirkus, 2019, s.12).

Umożliwia ona zaistnienie sytuacji realnego, a nie pozornego, dialogu między mistrzem ignorantem (nieprzywiązującym wagi do arbitralnie narzuconych nierówności w relacjach nauczyciel-uczeń) a dzieckiem. Młody człowiek określany jest w tej relacji jako mówca, który posiada i realizuje swoje prawo do zabierania głosu. Za pośrednictwem aktu mowy dziecko realizuje swoją podstawową umiejętność jako człowiek (Rancière, 1991). Używając głosu, konstruuje wiedzę, a nie ją odtwarza. Taka praktyka umożliwia zaistnienie relacji między uczniem i nauczycielem, opartych na rzeczywistej równości tych dwóch podmiotów (dwóch inteligencji), co jest kluczowe dla realizacji kultury praw dziecka w szkole.

Kultura praw dziecka w szkole sytuuje się pomiędzy kulturą dominującą a kulturą oporu (ryc. 1). Jej hybrydyczność wynika z konstytuującego ją aspektu normatywnego i nienormatywnego. Do jej zaistnienia konieczne jest jednoczesne wystąpienie czterech elementów: partycypacji, upełnomocnienia, świadomości praw oraz szacunku dla nich (Brantefors, Tellgren i Thelander, 2019). Partycypacja wyraża się w realnym uczestnictwie uczniów w życiu codziennym szkoły. Upełnomocnienie zaś dotyczy stworzenia warunków do angażowania się dzieci w ważne dla nich sprawy. Kolejny aspekt, świadomość praw, wiąże się z kwestią edukacji poprzez praktykę. Szacunek dla praw natomiast wyraża się w rozwijaniu pozytywnych relacji społecznych w szkole i respektujących prawa wszystkich uczestników.

Kultura praw dziecka wyrasta z przekonania, że prawa człowieka i prawa dziecka nie mogą być sprowadzone do przedmiotu szkolnego. Odzwierciedlać się one muszą we wszystkich aktywnościach edukacyjnych (Brantefors, Tellgren i Thelander, 2019). Nie mogą być traktowane jako teoretyczne zapisy, po które można sięgnąć jedynie w skrajnych sytuacjach. Ich znaczenie urealnia się w codziennych praktykach, co sprawia, że nie są one traktowane przez dzieci i dorosłych jak sytuacje wyjątkowe, lecz jako niekwestionowana rzeczywistość rozwoju podmiotu.

Kultura praw dziecka to wzory zachowań, relacji, przestrzeń materialna i symboliczna, system wartości i norm, które w centrum stawiają byt ludzki, jakim jest dziecko, i przynależne jemu prawa. Kluczową rolę odgrywa tu proces partycypacji rozumiany jako wspólne zaangażowanie uczniów i nauczycieli, którzy współdziałają, współdecydują o różnych obszarach życia szkoły 
(Coleman, 2010; Jarosz, 2016, 2018). „Partycypacja oznacza możliwość uczestniczenia w decyzjach i wpływania na decyzje oraz możliwość angażowania się przez młodych ludzi w działalność dla wspólnego dobra" (Jarosz, 2016, s. 70). Punktem wspólnym tych działań jest dobro dziecka jako jednostki i jako członka społeczeństwa (obywatela).

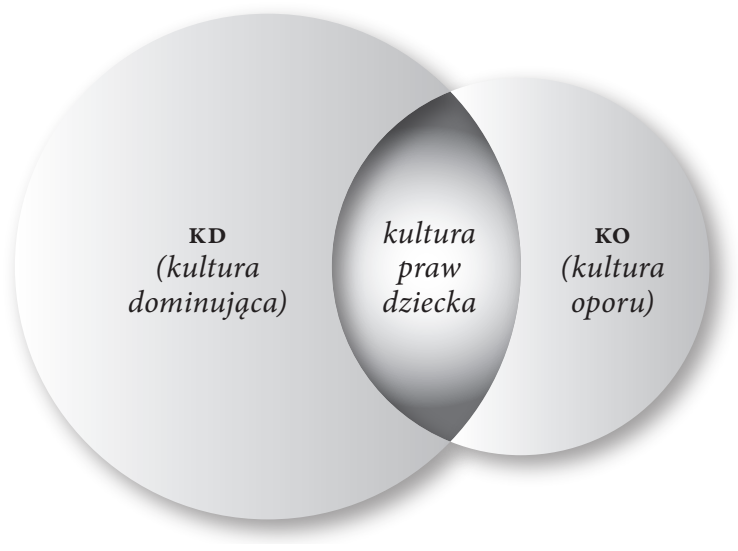

\section{Rycina 1. Kultura praw dziecka}

Źródło: opracowanie własne

Według zaleceń UNICEF (2007), dotyczących krzewienia w procesie edukacji podejścia bazującego na prawach człowieka, szkoły powinny adaptować się do dzieci, a nie dzieci do szkół.

Prawa człowieka muszą zostać włączone do wszystkich polityk szkolnych poprzez negocjacje i zaangażowanie wszystkich członków społeczności szkolnej, aby dzieci i nauczyciele byli świadomi swoich praw i wynikających z nich obowiązków oraz sposobu ich wykonywania (UNICEF, 2007, s. 76).

Kultura praw dziecka bazuje nie tylko na wiedzy nauczycieli i uczniów dotyczącej kwestii prawnych w tym zakresie, ale przede wszystkim na codziennych praktykach. Kluczowym elementem jest tu implementacja praw dziecka i praw człowieka w rzeczywistość szkoły, co zmienia obowiązujące w niej nieegalitarne, oparte na adultarchii standardy (Śliwerski, 2007), dające przywileje tylko grupie dorosłych.

Potraktowanie praw dziecka jako praw naturalnych, niebędących prostym przeciwstawieniem dla porządku prawnego ustanowionego przez państwo, lecz raczej pewnym punktem odniesienia krytycznej refleksji, powinno sprzyjać powołaniu 
instytucji i procedur tworzenia i gwarantowania prawa skoncentrowanego wokół tego, co z natury słuszne, chroniących i precyzujących ten sens, a zatem tworzących racjonalny consensus towarzyszący tym działaniom (Śliwerski, 2007, s.65).

Kozak (2014, s. 29), wskazując na znaczenie dla rozwoju indywidualnego i społecznego uczniów edukacji na rzecz praw dziecka, określiła trzy kształtujące tę edukację elementy: edukację o prawach dziecka (komponent wiedzy), edukację do realizacji idei praw dziecka (komponent umiejętności) i edukację poprzez prawa dziecka (komponent społeczny). Odnosząc wskazane przez autorkę elementy do szerszego zakresu, jakim jest kultura praw dziecka w szkole, można powiedzieć, że krzewienie tej kultury oparte jest na tych komponentach, które współdziałają w przestrzeni codziennego życia szkoły. Zawarta jest w nich zasada trzech „P” (Provision - Zaspokojenie potrzeb, Protection - Ochrona i Participation - Partycypacja), która legła u podstaw zapisów w Konwencji o prawach dziecka (Levy, 2018). Zasada trzech „P” stanowi wyznacznik dla tworzenia kultury praw dziecka w szkole jako elementu kultury praw człowieka w społeczeństwie demokratycznym.

\section{Po co w szkole kultura praw dziecka?}

Madalińska-Michalak (2014), odwołując się do Szewczyka (1998), podkreśla, że w zawodzie nauczycielskim szczególnie istotne są trzy wartości, które określane są mianem wartości autotelicznych. Należą do nich: odpowiedzialność, dobro dziecka oraz wychowanie człowieka mądrego. Wszystkie one mieszczą się w ramach zakreślonych przez prawa dziecka i stanowią cele edukacji określone w artykule 29. KPD, który mówi, że:

Państwa-Strony są zgodne, że nauka dziecka będzie ukierunkowana na:

1. rozwijanie w jak najpełniejszym zakresie osobowości, talentów oraz zdolności umysłowych i fizycznych dziecka,

2. rozwijanie w dziecku szacunku dla praw człowieka i podstawowych swobód oraz dla zasad zawartych w Karcie Narodów Zjednoczonych,

3. rozwijanie w dziecku szacunku dla jego rodziców, jego tożsamości kulturowej, języka i wartości, dla wartości narodowych kraju, w którym mieszka dziecko, kraju, z którego dziecko pochodzi, jak i dla innych kultur,

4. przygotowanie dziecka do odpowiedniego życia w wolnym społeczeństwie, w duchu zrozumienia, pokoju, tolerancji, równości płci oraz przyjaźni pomiędzy wszystkimi narodami, grupami etnicznymi, narodowymi i religijnymi oraz osobami rdzennego pochodzenia,

5. rozwijanie w dziecku poszanowania środowiska naturalnego. 
Jednym z istotnych obszarów implementacji praw dziecka jest system edukacji, a nauczyciele, jako przedstawiciele (agents) instytucji edukacyjnych, pełnią istotną rolę w tym procesie (Jerome, 2012). W szkole edukacja odbywająca się $\mathrm{w}$ atmosferze poszanowania i praktykowania praw dziecka oraz praw człowieka może mieć miejsce, gdy dzieci i nauczyciele będą razem uczyć się, bawić oraz żyć (United Nations, 2001). Należy zaznaczyć, że nie chodzi o teoretyczne uczenie praw dziecka w ramach określonego przedmiotu, do którego wystarczająca byłaby wiedza nauczyciela z tego zakresu. Chodzi o życie w szkole, które odbywać się będzie w kulturze praw dziecka. Aby sytuacja taka była możliwa, konieczne jest urzeczywistnianie dialogu między uczniami i nauczycielami. Dialog ten nie może nosić znamion pozoru (Dudzikowa, 2013), który sprowadza się do stworzenia ułudy nieskrępowanej i otwartej wymiany myśli i poglądów. Niezbędnym wymogiem jest tu nie tylko wysłuchanie dziecka, ale także stworzenie mu możliwości do wypowiedzenia się (United Nations, 2009). Szczególne zastosowanie ma tu artykuł 12. KPD, który mówi o prawie dziecka do wyrażania swoich poglądów we wszystkich sprawach jego dotyczących.

Według Lundy (2007) artykuł 12. KPD należy rozumieć w szerszym sensie niż tylko prawo dziecka do użycia głosu. Samo posłużenie się głosem, wyrażenie opinii nie jest wystarczające, aby prawo zapisane w artykule 12. zostało zrealizowane. Lundy (2007) proponuje nowy model rozumienia artykułu 12. KPD. Według autorki implikacja tego zapisu powinna być rozważana w czterech sferach: przestrzeni, głosie, publiczności i wplywie (Lundy, 2007, s. 932-933). Wszystkie te sfery są współzależne. Pierwszym elementem zabezpieczenia realizacji tego prawa jest przestrzeń, rozumiana jako stworzenie dziecku możliwości, warunków do wyrażenia swoich poglądów. Element głosu wyraża się w umożliwieniu dziecku ekspresji swoich poglądów. Publiczność zaś sprowadza się do wysłuchania tego, co dziecko ma do powiedzenia. Wpływ natomiast odnosi się do odpowiedniego uwzględnienia poglądów dziecka. Dziecko powinno odczuć, że jego opinie mają znaczenie i rzeczywiście są brane pod uwagę przez nauczycieli oraz przez innych członków instytucji edukacyjnych (Perry-Hazan, 2015, Ribaeus i Skånfors, 2019). Zaproponowane przez Lundy (2007) rozumienie artykułu 12. Konwencji o prawach dziecka wpisuje się w opisane przez McLamon (2008) podejście do praw dziecka, zgodnie z którym każde dziecko, niezależnie od wieku, jest w stanie pokazać/powiedzieć dorosłym, co jest dla niego ważne. Należy go wysłuchać, oraz przemyśleć to, co dziecko przekazało, a także odpowiednio zareagować. Wówczas dziecko będzie doświadczało siebie jako podmiotu mającego wpływ na otaczającą go rzeczywistość. 
Wyrażanie własnych poglądów przez dziecko i uwzględnianie ich przez nauczycieli jest kluczowym elementem partycypacji dziecka w środowisku edukacyjnym (James i James, 2012; Ribaeus i Skånfors, 2019), a co za tym idzie urzeczywistniania kultury praw dziecka w szkole. Proces konsultacji z dziećmi, o którym pisze między innymi Rudduck (2007), McIntyre i in. (2005) ma znaczenie dla ich realnej partycypacji w życiu instytucji edukacyjnej. Partycypacja zaś wyraża się w angażowaniu uczniów w prace szkoły $\mathrm{w}$ różnych wymiarach i zapewnieniu im uczestnictwa w podejmowaniu decyzji dotyczących istotnych aspektów działania tej instytucji (Lansdown, 2011; Simó Gil i in., 2017). Partycypacja wiąże się nie tylko z podejmowaniem aktywności, ale też z ponoszeniem konsekwencji swoich działań, co uczy także odpowiedzialności (Rudduck, 2007, Jerome, 2012).

Zapewnienie dziecku wskazanych przez Lundy (2007) warunków realizacji prawa do swoich poglądów sprawia, że staje się ono aktywnym twórcą dyskursu szkolnego. Dyskurs ten zaś, w rozumieniu, jakie przyjmuję za Rancière (1999), tworzony jest przez podmioty, których głos jest słyszany, rozumiany i traktowany z należytą powagą. Oznacza to, że szkoła realizuje wówczas strategię VIP (Voice-Inclusive Practice), która polega na aktywnym angażowaniu dzieci we wszystkie sprawy szkoły, które są dla nich ważne (Sargeant i Gillett-Swan, 2019). Strategia ta zmienia też pozycję nauczyciela, który staje się rzecznikiem zmiany, który posiada umiejętność po/myślenia na nowo (Gołębniak i Zamorska, 2014) sytuacji edukacyjnej i/lub kultury szkoły.

\section{Podsumowanie}

W artykule sygnalizuję konieczność poddania pod refleksję nauczycieli nauczycieli kwestii znaczenia przygotowania przyszłych nauczycieli do krzewienia kultury praw dziecka w szkole. Konieczność tego przygotowania uznaję za istotny element profesjonalizmu nauczycieli, który ogniskuje się wokół umiejętności budowania opartych na prawach dziecka i prawach człowieka relacji z uczniami oraz innymi uczestnikami życia szkoły. Profesjonalizm nauczyciela wyraża się nie tylko w jego profesjonalizacji i specjalizacji, ale przede wszystkim w trosce o człowieczeństwo w relacjach dydaktycznych i szkolnych (por. Gołębniak, 2008; Olubiński, 2012; Babicka-Wirkus, 2019b; Szplit 2019). Człowieczeństwo natomiast jest wymiarem jednostki, wokół którego koncentruje się idea praw dziecka i praw człowieka. Realizacja tego wymiaru w codzienności szkoły jest możliwa tylko wtedy, gdy jej działanie będzie bazowało na praktykowaniu kultury praw dziecka. Kluczową rolę odgrywa tu nauczyciel. 
Z perspektywy idei praw dziecka i praw człowieka nauczyciel jest profesjonalistą, gdy posiada pełną wiedzę na temat tych praw i zrozumie ich istotę. Wówczas możliwa jest edukacja oparta na zasadzie równości, w której głos dziecka, jak i nauczyciela, jest tak samo znaczący, ponieważ obie jednostki są bytami ludzkimi. Poprzez taką praktykę nauczyciel jest w stanie dokonać rzeczywistej i głębokiej transformacji, lokującej się na poziomie myślenia o świecie i relacjach z innymi ludźmi: młodszymi, starszymi, reprezentantami odmiennych kultur, wyznań, orientacji seksualnych (Babicka-Wirkus, 2019b). Jego pozycja przekracza wówczas tak zwany standard przedmiotowy, o którym pisze Kwiatkowska (2008) i który przejawia się w uprzedmiotawianiu uczniów. Nauczyciel respektujący i rozwijający kulturę praw dziecka w szkole kieruje się standardem autonomii, afirmującym wolność i niezależność zarówno swoją, jak i uczniów. Jest to istotne z perspektywy przygotowania młodych ludzi do aktywnego uczestnictwa w społeczeństwie demokratycznym (Śliwerski, 2013), a także z perspektywy efektów uczenia się oraz kompetencji społecznych wskazanych w standardzie kształcenia przygotowującego do zawodu nauczyciela (Rozporządzenie Ministra Nauki i Szkolnictwa Wyższego z dnia 25 lipca 2019 r.).

W niniejszym tekście nie podaję odpowiedzi na pytanie: jak przygotować nauczycieli do implementacji w życie szkoły praw dziecka i człowieka? To zagadnienie, podjęte już w pewnym zakresie przez Kozak (2014), wymaga szerszego namysłu, szczególnie w kontekście obecnych problemów, z jakimi zmaga się polska szkoła, takimi jak: przepełnione klasy, niski prestiż zawodu nauczycielskiego, pandemia koronawirusa, problemy ze zdalnym nauczaniem, niemożność nawiązania dialogu między nauczycielami a Ministerstwem Edukacji Narodowej, wzrost depresji wśród młodych ludzi itp. Bolączki te wprowadzają chaos w codzienne życie szkoły i sprawiają, że kwestie poszanowania i praktykowania praw dziecka w szkole schodzą na dalszy plan. Przeszkodą jest również istnienie spetryfikowanych i opartych na nierównościach relacji między nauczycielami a uczniami, w których nauczyciel znajduje się w pozycji uprzywilejowanej względem ucznia (nierówność inteligencji). Zmiana tych relacji możliwa jest poprzez implementację w codzienne życie szkoły praw człowieka i praw dziecka, które opierają się na równości wszystkich ludzi. Namysł nad stworzeniem takich relacji w szkole powinien rozpocząć się już w trakcie przygotowania nauczycieli do zawodu. Konieczne jest zatem, aby umiejętność po/myślenia na nowo (Gołębniak i Zamorska, 2014) relacji w szkole stała się kluczowym elementem profesjonalizmu nauczycieli. 


\section{BIBLIOGRAFIA}

Babicka-Wirkus, A. (2018). Respektowanie prawa do autoekspresji a rytuały oporu gimnazjalistów. Warszawa: Biblioteka Rzecznika Praw Dziecka.

Babicka-Wirkus, A. (2019a). Kultury oporu w szkole. Działania - motywacje - przestrzeń. Warszawa: Wolters Kluwer.

Babicka-Wirkus, A. (2019b). Children's Rights and Human Rights as a Key Condition for the Education of Transformative Teachers. W: M. Kowalczuk-Walędziak, A. Korzeniecka-Bondar, W. Danilewicz, G. Lauwers (red.), Rethinking Teacher Education for the $21^{\text {st }}$ Century. Trends, Challenges and New Directions, (s. 239-252). Leverkusen-Opladen: Verlag Barbara Budrich.

Babicka-Wirkus, A., Groenwald, M. (2018). Głos dziecka w przedszkolu - między swobodą wypowiedzi a milczeniem. Problemy Wczesnej Edukacji, 1 (40), 95-104.

Brantefors, L., Tellgren, B., Thelander, N. (2019). Human Rights Education as Democratic Education. The Teaching Traditions of Children's Human Rights in Swedish Early Childhood Education and School. The International Journal of Children's Rights, 27 (4), 694-718. Doi:10.1163/15718182-02704007.

Coleman, J. (2010). The nature of adolescence. London: Routledge.

Czerepaniak-Walczak, M. (1997). Źródła i aspekty profesjonalnej refleksji nauczyciela. Toruń: Wydawnictwo Edytor.

Czerepaniak-Walczak, M. (2015). Kultura szkoły - o jej złożoności i wielowymiarowości. Pedagogika Społeczna, 3 (57).

Czerepaniak-Walczak, M. (2018). Proces emancypacji kultury szkoły. Warszawa: Wolters Kluwer.

Demirkasīmoğlu, N. (2010). Defining „Teacher Professionalism” from different perspectives. Procedia - Social and behavioral Sciences, 9, 2047-2051. https://doi.org/10.1016/ j.sbspro.2010.12.444

Dudzikowa, M. (2013). Użyteczność pojęcia działań pozornych jako kategorii analitycznej. Egzemplifikacje z obszaru edukacji (i nie tylko). W: M. Dudzikowa, K. Knasiecka-Falbierska (red.), Sprawcy i/lub ofiary działań pozornych w edukacji szkolnej (s. 27-82). Kraków: Oficyna Wydawnicza Impuls.

Dudzikowa, M., Jaskulska, S. (red.). (2016). Twierdza. Szkoła w metaforze militarnej. Co wzamian? Warszawa: Wolters Kluwer.

Dudzikowa, M., Knasiecka-Falbierska, K. (red.). (2013). Sprawcy i/lub ofiary działań pozornych w edukacji szkolnej. Kraków: Oficyna Wydawnicza Impuls.

Englund, T. (1996). Are Professional Teachers a Good Thing. W: I.F. Goodson, A. Hargreaves (red.), Teachers' Professional Lives (s. 75-87). London: Falmer Press.

Gołębniak, B.D. (2008). Pytanie o szkołę wyższą. W trosce o człowieczeństwo. Wrocław: Wydawnictwo Naukowe DSW.

Gołębniak, B.D., Zamorska, B. (2014). Nowy profesjonalizm nauczycieli. Podejścia - praktyka - przestrzeń rozwoju. Wrocław: Dolnośląska Szkoła Wyższa.

Jabłoński, M., Jarosz-Żukowska S. (2004). Prawa człowieka i system ich ochrony. Zarys wykła$d u$. Wrocław: Wydawnictwo Uniwersytetu Wrocławskiego.

James, A., James, A. (2012). Key Concepts in Childhood Studies. Wyd. 2. Los Angeles-London-New Delhi-Singapore-Washington, DC: Sage.

Jarosz, E. (2016). Partycypacja dzieci a rozwój zaangażowania obywatelskiego. Pedagogika Społeczna, 2 (60), 67-87.

Jarosz, E. (2018). Partycypacja społeczna dzieci - szkic z rozwoju interdyscyplinarnego dyskursu. W: M. Michalak (red.), Prawa dziecka wczoraj, dziś i jutro - perspektywa korczakowska (s. 285-303). T. 2. Warszawa: Biuro Rzecznika Praw Dziecka.

Jerome, L. (2012). Children's Rights and Teachers' Responsibilities. A Case Study of Developing a Rights Respecting Initial Teacher Education Programme. W: R.C. Mitchell, S.A. Moore 
(red.), Policies, Participation \& Power Relations (s. 101-117). Rotterdam-Boston-Taipei: Sense Publishers.

Jerome, L. Emerson, L., Lundy, L., Orr, K. (2015). Teaching and Learning about Child Rights: A Study of Implementation in 26 Countries. QUB \& UNICEF. Pozyskano z: https://www. researchgate.net/publication/299454868_Teaching_and_learning_about_child_rights_ a_study_of_implementation_in_26_countries, [data dostępu: 23.08.2018].

Klus-Stańska, D. (2010). Dzień jak co dzień. O barierach zmiany kultury szkoły. W: M. Dudzikowa, M. Czerepaniak-Walczak (red.), Wychowanie. Pojęcia - procesy - konteksty (s. 301-326). T. 5. Gdańsk: Gdańskie Wydawnictwo Psychologiczne.

Kozak, M. (2014). Edukacja na rzecz praw dziecka w szkole wyższej. Zasady dydaktyki szczegółowej. Kraków: Oficyna Wydawnicza Impuls.

Kwiatkowska, H. (2008). Pedeutologia. Warszawa: Wydawnictwa Akademickie i Profesjonalne.

Lansdown, G. (2011). Every Child's Right to be Heard. A resource guide on the UN Committee on the Rights of the Child general comment no. 12. UNICEF. The Save the Children Found. Pozyskano z: https://www.unicef.org/french/adolescence/files/Every_Childs_Right_to_ be_Heard.pdf [data dostępu: 25.02.2019].

Lawin, M. (1996). Modern Times?: Work, Professionalism and Citizenship in Teaching. London-Washington, DC: The Falmer Press.

Levy, J. (2018). Demokracja zaczyna się tam, gdzie prawa dziecka. W: M. Michalak (red.), Prawa dziecka wczoraj, dziś i jutro - perspektywa korczakowska (s. 321-333). T. 2. Warszawa: Biuro Rzecznika Praw Dziecka.

Lundy, L. (2007). „Voice” is not enough: conceptualizing Article 12 of the United Nations Convention on the Rights of the Child. British Educational Research Journal, 33(6), 927-942. doi: 10.1080/01411920701657033.

Madalińska-Michalak, J. (2014). Profesjonalizm nauczyciela. Mazowiecki Kwartalnik Edukacyjny - Meritum, 1 (32), 2-10.

McIntyre, D., Pedder, D., Rudduck, J. (2005). Pupil voice: comfortable and uncomfortable learnings for teachers. Research Papers in Education, 20(2), 149-168. doi: 10.1080/026715205 00077970

McLamon, J. (2008). Listening as a Way of Life - Supporting Parents and Carers to Listen: A Guide for Practitioners. London: National Children's Bureau/DCSF.

Nowak-Dziemianowicz, M. (2008). „Wielki Przegrany Współczesności”. Polski nauczyciel jako podmiot i przedmiot kształcenia. W: P. Rudnicki, B. Kutrowska, M. Nowak-Dziemianowicz (red.), Nauczyciel: misja czy zawód? Społeczne i profesjonalne aspekty roli (s. 129-162). Wrocław: Wydawnictwo Naukowe Dolnośląskiej Szkoły Wyższej.

Olubiński, A. (2012). Podmiotowość roli nauczyciela i ucznia (w świetle analiz opinii społecznych). Toruń: Wydawnictwo Adam Marszałek.

Osiatyński, W. (2011). Prawa człowieka i ich granice. Przeł. S. Kowalski. Kraków: Społeczny Instytut Wydawniczy Znak.

Perry-Hazan, L. (2015). Freedom of Speech in Schools and the Right to Participation: When the First Amendment Encounters the Convention on the Rights of the Child. Brigham Young University Education and Law Journal, 2, 421-452.

Rancière, J., (1991). The Ignorant Schoolmaster. Five Lessons in Intellectual Emancipation. Przeł. K. Ross. Stanford: Stanford University Press.

Rancière, J. (1999). Dis-agreement: Politics and Philosophy. Przeł. J. Rose. Minnesota: University of Minnesota.

Ribaeus, K., Skånfors, L. (2019). Preschool Children as Democratic Subjects: Agents of Democracy. W: V. Margrain, A. Löfdahl Hultman (red.), Challenging Democracy in Early Childhood Education. Engagement in changing global contexts (s. 233-245). Singapore: Springer. 
Rozporządzenie Ministra Nauki i Szkolnictwa Wyższego z dnia 25 lipca 2019 r. w sprawie standardu kształcenia przygotowującego do wykonywania zawodu nauczyciela. Dz.U. 2019, poz. 1450.

Rudduck, J. (2007). Student Voice, Student Engagement, and School Reform. W: D. Thiessen, A. Cook-Sather (red.), International Handbook of Student Experience in Elementary and Secondary School (s. 587-610). Dordrecht: Springer Netherlands.

Sargeant, J., Gillett-Swan, J.K. (2019). Voice-Inclusive Practice (VIP): A Charter for Authentic Student Engagement. The International Journal of Children's Rights, 27(1), 122-139. doi: 10.1163/15718182-02701002

Simo-Gil, N., Parareda Pallarès, A., Tellado, I. (2017). Learning Democracy in Schools: Experienes Towards an Active Citizenship Education. Social Studies: Theory and Practice, 3 (2), 63-79.

Snoek, M. (2009). Theories on and concepts of professionalism of teachers and their consequences for the curriculum in teacher education. Pozyskano z: https://pdfs.semanticscholar. org/756o/a953f19897334e444aad6feb37bc9ce41cbc.pdf, [data dostępu: 25.05.2020].

Szewczyk, K. (1998). Wychować człowieka mądrego. Zarys etyki nauczycielskiej. WarszawaŁódź: PWN.

Szplit, A. (2019). Od nowicjusza do eksperta. Rozwój ekspertywności nauczycieli nauczycieli języków obcych. Kielce: Wydawnictwo Uniwersytetu Jana Kochanowskiego.

Śliwerski, B. (2007). Pedagogika dziecka. Stadium pajdocentryzmu. Gdańsk: Gdańskie Wydawnictwo Psychologiczne.

Śliwerski, B. (2013). Diagnoza uspołecznienia publicznego szkolnictwa III RP w gorsecie centralizmu. Kraków: Oficyna Wydawnicza Impuls.

UNICEF (2007). A Human Rights-Based Approach to Education for All. A framework for the realization of children's rights to education and rights within education. Pozyskano z: https://unesdoc.unesco.org/ark:/48223/pfoooo154861, [data dostępu: 13.06.2020].

United Nations. Committee on the Rights of the Child (2001). General Comment No. 1. Article 29. The Aims of Education (CRC/GC/2001/1). Geneva, Switzerland. Pozyskano z: https://www. refworld.org/docid/4538834d5.html, [data dostępu: 25.05.2020].

United Nations. Committee on the Rights of the Child (2009). General Comment No. 12 The right of the child to be heard (CRC/C/GC/12). Geneva, Switzerland. Pozyskano z: https:// www.refworld.org/docid/4ae562c52.html, [data dostępu: 25.05.2020].

\section{SUMMARY}

\section{Teacher's professionalism and children's rights culture in school}

The article deals with the issue of implementing the culture of children's rights in school and the role of a professional teacher in this process. Practicing this culture in everyday school life is a task that requires the teacher not only to have a thorough knowledge of the rights of the child and human rights, but also to accept these ideas and create opportunities to experience and claim them at school. The academic and colloquial discourse on teacher professionalism ignores or marginally treats this dimension, which results in a low level of practice of children's rights culture in schools. This state is also important for the quality of citizens' preparation for life in a democratic civil society based on human and children's rights.

KEYWORDS: children's rights culture, teacher's professionalism, school 